\title{
GMR
}

\section{Analysis of imprinted messenger RNA expression in deceased transgenic cloned goats}

\author{
R.X. Jia, Z.R. Zhou, G.M. Zhang, L.Z. Wang, Y.X. Fan, Y.J. Wan, Y.L. Zhang, \\ Z.Y. Wang and F. Wang \\ Jiangsu Livestock Embryo Engineering Laboratory, Nanjing Agricultural University, \\ Nanjing, China \\ Corresponding author: F. Wang \\ E-mail: caeet@njau.edu.cn \\ Genet. Mol. Res. 15 (1): gmr.15017455 \\ Received August 14, 2015 \\ Accepted October 29, 2015 \\ Published January 29, 2016 \\ DOI http://dx.doi.org/10.4238/gmr.15017455
}

ABSTRACT. Genomic imprinting is an important epigenetic mechanism that has vital effects on fetal growth and development. We observed the differences in four tissues (heart, spleen, liver, and kidney) from dead transgenic cloned goats using hematoxylin and eosin (H\&E) staining. Eight imprinted genes in the tissues of dead transgenic cloned and normal goats were analyzed using reverse transcription polymerase chain reaction. $\mathrm{H} \& \mathrm{E}$ staining results from the abortion group indicated the lack of obvious morphological changes in heart and spleen tissues, while inflammatory cell infiltration and glomerular nephritis characteristics were observed in liver and kidney tissues, respectively. Compared to the control group, CDKN1C, $H 19, I G F 2 R$, and SNRPN were significantly $(\mathrm{P}<0.05)$ overexpressed in the heart tissue of the abortion group, while XIST was significantly reduced. In the liver tissues, CDKN1C and DLK1 expression decreased, while GNAS, H19, IGF2R, PEG3, and XIST expression increased significantly. In the spleen tissues, DLK1 expression increased, while GNAS, H19, IGF2R, $P E G 3, S N R P N$, and XIST expression decreased. In the kidney tissues, CDKN1C, DLK1, GNAS, IGF2R, and PEG3 expression increased, while H19 and XIST expression decreased. The overall expression of imprinted genes was abnormal in different tissues of transgenic cloned goats, and the 
degree of abnormal genomic imprinting was more severe in the abortion group compared to the death and control groups. These results suggest that abnormal expression of imprinted genes may cause developmental defects in transgenic cloned goats. Moreover, abnormal epigenetic modifications may affect the reprogramming of transgenic donor cells.

Key words: Imprinted gene; Transgenic cloned goat

\section{INTRODUCTION}

The cloning of livestock animals by somatic cell nuclear transfer (SCNT) has been successfully achieved in a wide range of mammals, including a number of domestic species. However, there is a high incidence of abnormalities in SCNT clones, including low birth rate, placental dysfunctions, and large offspring syndrome (LOS), which collectively appear to be a great barrier to efficient cloning (Constant et al., 2006; Yang, et al., 2007; Bischoff et al., 2009).

The incomplete reprogramming of donor somatic cell nuclei, leading to aberrant (or even a lack of) expression of some developmentally important genes, has been implicated as a primary reason for this low efficiency. Genomic imprinting is an epigenetic mechanism that greatly impacts normal mammalian development.

Imprinted genes play important roles in embryo survival and postnatal growth regulation. Cyclin-dependent kinase inhibitor $1 \mathrm{C}(C D K N 1 C)$ is a potent inhibitor of several G1 cyclin/CDK complexes, and its overexpression leads to cell-cycle arrest in the G1 phase (Madhavan et al., 2010). Drosophila-like homolog 1 (DLK1) is a transmembrane signal protein with key roles in differentiation, and it controls several cell-differentiation processes throughout the embryonic and adult life cycles (Oczkowicz et al., 2010). Guanine nucleotide binding protein, alpha stimulating (GNAS) complex locus is a complex imprinted gene, which is required for normal fetal growth and development, and this transcript affects placental functions (Richard et al., 2013). H19 and insulin-like growth factor-2 receptor (IGF2R) are among the best-studied imprinted genes involved in fetal growth regulation, and both are essential for normal development (Yang et al., 2005). The imprinted gene, paternally expressed gene 3 (PEG3), alters growth and development and regulates apoptosis (Jiang et al., 2010). SNRPN (small nuclear ribonucleoprotein polypeptide N) is a member of a gene family that encode proteins involved in pre-mRNA splicing and alternative RNA processing, which has been extensively studied due to correlations with cell differentiation, proliferation, and embryogenesis (Suzuki et al., 2009; Couldrey and Lee, 2010; Wang et al., 2012). X-inactive specific transcript (XIST), a long non-coding RNA, plays an important role in early embryonic development (Matoba et al., 2011).

Several studies of imprinted genes have been conducted using the pre-implanted embryos (Wrenzycki et al., 2004), placentas (Su et al., 2011), and fetuses (Ogawa et al., 2003) of cloned animals (e.g., mice, calves, and swine). However, there are limited studies that utilized transgenic cloned goats, especially the internal organs of these animals. Moreover, abnormal expression of imprinted genes in critical organs may cause the death of transgenic cloned animals. The objective of the present study was to investigate the expression of eight imprinted genes (CDKN1C, DLK1, GNAS, H19, IGF2R, SNRPN, PEG3, and XIST) in the heart, liver, spleen, and kidneys of transgenic cloned and normal goats to reveal possible genetic causes of death in transgenic cloned goats. 


\section{MATERIAL AND METHODS}

\section{Production of transgenic goats and sample collection}

Deceased human lactoferrin $(h L F)$ transgenic cloned goats were collected from previous studies that produced the goats using SCNT (Wan et al., 2012). Briefly, goat fibroblast cells from the ears of three-month-old goats were used to produce donor somatic cells harboring $h L F$ for SCNT. Culture and passage of donor cells, oocyte collection and enucleation, nuclear transfer, oocyte activation, embryo culture, and embryo transfer were carried out in order (Wan et al., 2012). Normal goats of the same age, produced using conventional reproduction, were used as controls.

The transgenic cloned goats and three normal goats, with the same genetic background, were cultivated under the same husbandry conditions. The deceased transgenic goats were divided into two groups: 1) the abortion group included goats that died before the expected birth date, including four transgenic cloned goats; 2 ) the born dead group (D) included animals that died in 3 days after birth, including three transgenic cloned goats. The normal group $(\mathrm{N})$ included three newborn normal goats produced via conventional reproduction, which is the control group.

\section{Tissue collection}

The tissues were collected immediately after the death of transgenic cloned goats and after the killing (overdose with barbiturate) of normal control goats. Some tissues were quickly frozen in liquid nitrogen and stored at $-80^{\circ} \mathrm{C}$. Other tissues were fixed in $4 \%$ formaldehyde for 24 $\mathrm{h}$, and were then stored in $75 \%$ alcohol. Fixed tissues were analyzed for structural organization, whereas tissues in nitrogen were analyzed for the expression of imprinted gene mRNA. Animal handling and experimentation were in accordance with the National Research Council's publication "Guide for the Care and Use of Laboratory Animals", and the methods used were approved by the Institutional Animal Care and Use Committees at Nanjing Agricultural University.

\section{Hematoxylin and eosin (H\&E) staining}

After fixation, tissues were embedded in paraffin, sectioned serially at $6 \mathrm{~mm}$, and mounted on slides. Sections were deparaffinized in xylene, and then rehydrated in a series of graded ethanol concentrations before staining with $\mathrm{H} \& \mathrm{E}$.

\section{RNA isolation}

Total RNA was extracted from the different tissues using the RNAprep Pure Tissue Kit (Tiangen, Beijing, China), according to the manufacturer protocol. RNA quality was confirmed using ratios of $A_{260} / A_{280}$ and $A 260 / A 230$ (Nanodrop, all between 1.8 and 2.0) and automated electrophoresis (BioRad Experion), which was based on the presence of three clear ribosomal RNA bands.

\section{cDNA preparation}

Reverse transcription was conducted using Transcriptor First Strand cDNA Synthesis Kit (Roche, USA). First, the template-primer mixture [1 $\mu \mathrm{g}$ total RNA, $1 \mu \mathrm{L}$ Anchored-oligo(dT)18 
Primer, $1.5 \mu \mathrm{L}$ random hexamer primer, and up to $13 \mu \mathrm{L}$ RNase-free $\mathrm{dH}_{2} \mathrm{O}$ ] was prepared. Second, the tube containing the template-primer mixture was heated for $10 \mathrm{~min}$ at $65^{\circ} \mathrm{C}$ to denature the secondary RNA structure. Third, $7 \mu \mathrm{L}$ of the remaining components of the RT mix were added to the template-primer mix (4 $\mu \mathrm{L} 5 X \mathrm{RT}$ buffer, $0.5 \mu \mathrm{L}$ Protector RNase Inhibitor, $2 \mu \mathrm{L}$ Deoxynucleotide Mix, and $0.5 \mu \mathrm{L}$ Transcriptor Reverse Transcriptase). Lastly, the RT reaction was incubated for 10 $\min$ at $25^{\circ} \mathrm{C}$, followed by $30 \mathrm{~min}$ at $55^{\circ} \mathrm{C}$, and the Transcriptor Reverse Transcriptase was then inactivated by heating the reactions for $5 \mathrm{~min}$ at $85^{\circ} \mathrm{C}$.

\section{Quantitative real-time PCR}

The expression levels of the eight imprinted genes were quantified using an $\mathrm{ABI} 7300$ real-time PCR detection system (Applied Biosystems, Foster City, CA, USA) with the FastStart Universal SYBR Green Master (Rox) (Roche, USA). The 12.5- $\mu \mathrm{L}$ reaction mixture contained 6.25

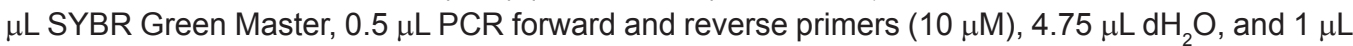
cDNA template. The PCR conditions were as follows: $95^{\circ} \mathrm{C}$ for $10 \mathrm{~min} ; 40$ cycles of $95^{\circ} \mathrm{C}$ for $15 \mathrm{~s}$, annealing for $30 \mathrm{~s}$ (annealing temperatures for each pair of primers are listed in Table 1), and $72^{\circ} \mathrm{C}$ for $30 \mathrm{~s}$. Melting curves were generated after amplification to check the specificity of the amplified product. The transcripts of nine imprinted genes were quantified using three replicates, and the quantification was normalized to an endogenous RNA control (the house-keeping gene GAPDH). The negative control was analyzed without a DNA template in the PCR mix.

Table 1. Primers for quantitative real-time polymerase chain reaction.

\begin{tabular}{|c|c|c|c|c|}
\hline Genes & Primer sequence $\left(5^{\prime}-3^{\prime}\right)$ & Product size (bp) & Sequence accession No. & Annealing temperature $\left({ }^{\circ} \mathrm{C}\right)$ \\
\hline CDKN1C & $\begin{array}{l}\text { F: GCCCATCTAGCTTGCAGTCTCT } \\
\text { R: CAGACGGCTCAGGAACCATT }\end{array}$ & 112 & NM_001142510 & 56.0 \\
\hline DLK1 & $\begin{array}{l}\text { F: GTGACCAGTGCGTGACCTTT } \\
\text { R: GCAGGTCTTGTCCATGAAGC }\end{array}$ & 454 & AY360448 & 54.0 \\
\hline GNAS & $\begin{array}{l}\text { F: GAAGGACAAGCAGGTCTACC } \\
\text { R: GACCATGTTGTAGCTGCTG }\end{array}$ & 675 & AY376066 & 60.0 \\
\hline$H 19$ & $\begin{array}{l}\text { F: GGACTGGAACTTGGACTTCTTCA } \\
\text { R: TGGTGTGGGTCTTCCGTTC }\end{array}$ & 133 & AY091484 & 55.5 \\
\hline IGF2R & $\begin{array}{l}\text { F: CCAGCGTCTGTGACTTCGTG } \\
\text { R: CCATCCTTGCAGCCTCCTTC }\end{array}$ & 220 & DQ666954 & 60.0 \\
\hline PEG3 & $\begin{array}{l}\text { F: CGCCAAAGTCAGGGAGAG } \\
\text { R: CTTAACTGCCAGGACACC }\end{array}$ & 150 & AY427787 & 60.0 \\
\hline SNRPN & $\begin{array}{l}\text { F: GGGACCGTTTACACTTGAGAC } \\
\text { R: GGAAATCCACCACAGGTACT }\end{array}$ & 153 & NM_174463 & 60.0 \\
\hline XIST & $\begin{array}{l}\text { F: AACCTCACGCCATTCCTCTG } \\
\text { R: GGGTAGGTGTTCCTCTTGAG }\end{array}$ & 226 & AF104906 & 56.0 \\
\hline GAPDH & $\begin{array}{l}\text { F: CGACTTCAACAGCGACACTCAC } \\
\text { R: CCCTGTTGCTGTAGCCCAATTC }\end{array}$ & 118 & NM_001034034 & 58.0 \\
\hline
\end{tabular}

$\mathrm{F}=$ forward $\mathrm{R}=$ reverse .

The RT-PCR results are presented as $C_{T}$ values (mean $\pm S D$ ), where $C_{t}$ was defined as the threshold PCR cycle number at which the amplified product was first detected. The $2^{-\Delta \Delta C t}$ method (Livak and Schmittgen, 2001) was used to quantify the relative mRNA levels using the following formula:

$$
\Delta \mathrm{C}_{\mathrm{t}}=\mathrm{C}_{\mathrm{t} \text { (target gene) }}-\mathrm{C}_{\mathrm{t}(\mathrm{GAPDH})} \text {, and } \Delta \Delta \mathrm{C}_{\mathrm{t}}=\Delta \mathrm{C}_{\mathrm{t} \text { (sample) }}-\Delta \mathrm{C}_{\mathrm{t} \text { (control) }}
$$

The relative mRNA levels were calculated as $2^{-\Delta \Delta c t}$. 


\section{Data and statistical analysis}

Data were reported as means \pm SEM, and the gene expression levels were analyzed using SPSS Statistics 17.0. Differences were considered significant at $P<0.05$.

\section{RESULTS}

\section{Tissues morphology of transgenic cloned goats}

Representative images of heart, liver, spleen, and kidney for each group are shown in Figures 1-4. No apparent veterinary developmental abnormalities were found in hearts and spleens of each group (Figures 1 and 3). However, compared to the liver tissues of the $\mathrm{N}$ group (Figure $2 A$ ), inflammation cells were present in livers of the $D$ and abortion groups (Figure $2 B$ and $C$ ). Furthermore, compared to the kidney tissues of the $\mathrm{N}$ group (Figure $4 \mathrm{~A}$ ), there were no apparent structural changes in kidneys of the D group (Figure 4B), but glomerular nephritis characteristics were observed in the kidneys of the abortion group (Figure 4C).

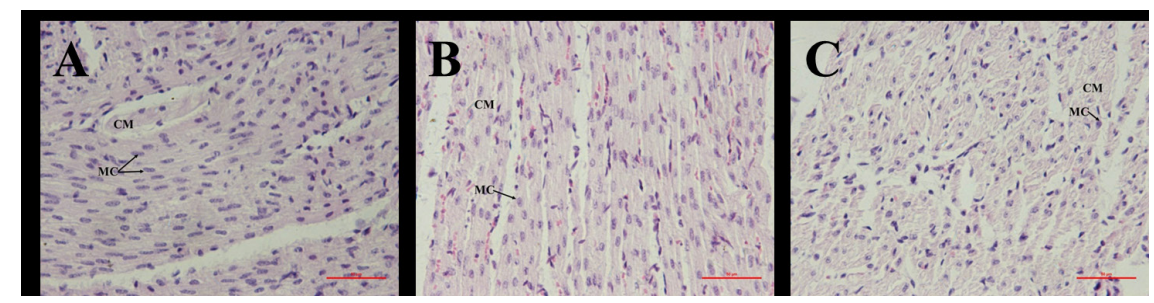

Figure 1. Cardiac morphology of transgenic cloned goats by H\&E staining. A. normal goat; B. postnatal death group; C. abortion group; $\mathrm{CM}=$ cardiac muscle; $\mathrm{MC}=$ myocardial cell.

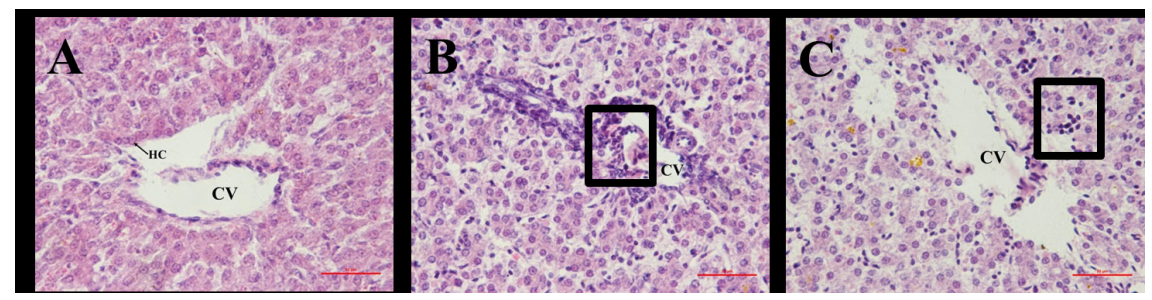

Figure 2. Hepatic morphology of transgenic cloned goats by H\&E staining. A. normal goat; B. postnatal death group; C. abortion group; $\mathrm{HC}=$ hepatocytes; $\mathrm{CV}=$ central veins; black box highlights labeled inflammatory cells.

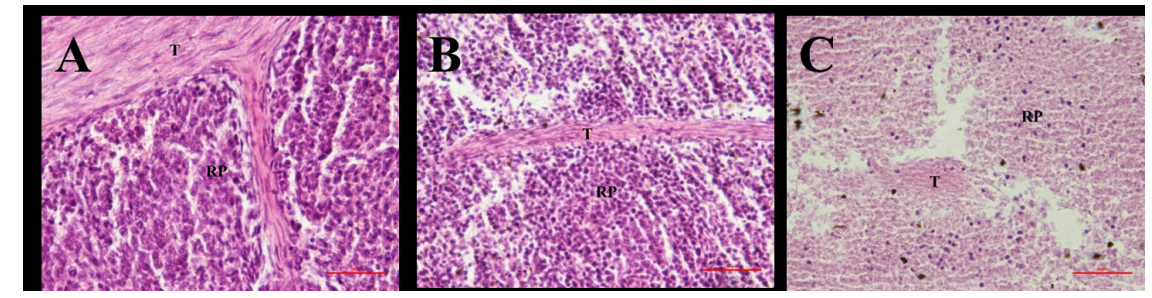

Figure 3. Splenetic morphology of transgenic cloned goats by H\&E staining. A. = normal goat; $\mathbf{B}$. postnatal death group; C. abortion group; $\mathrm{T}=$ trabecular; $\mathrm{RP}=$ red pulp. 


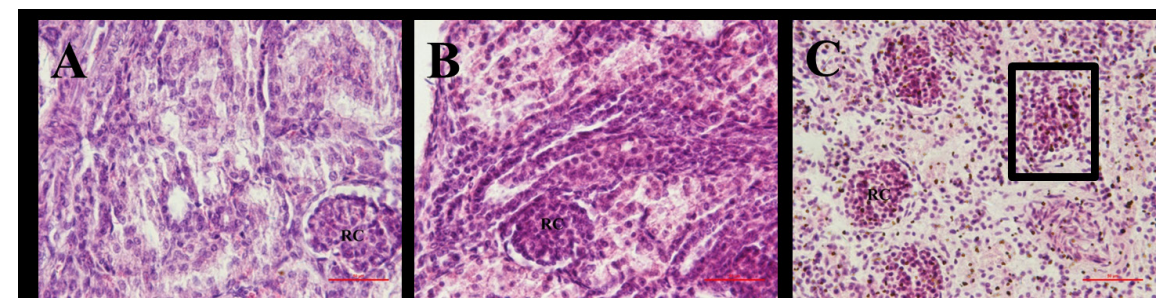

Figure 4. Renal morphology of transgenic cloned goats by H\&E staining. A. normal goat; B. postnatal death group; C. abortion group; RC = renal corpuscle; black box highlights labeled capsular space deficiency.

\section{Relative expression levels of imprinted genes in the heart}

The expression levels of $C D K N 1 C, H 19$, and IGF2R in the abortion group were significantly higher than that of the normal group (Figure 5A, D, and $\mathrm{E} ; \mathrm{P}<0.01, \mathrm{P}<0.01$, and $\mathrm{P}<0.05$, respectively) and the $D$ group (Figure $5 A, D$, and $E ; P<0.01, P<0.01$, and $P<0.01$, respectively). Moreover, notably significant differences were detected between the SNRPN expression levels of normal and dead transgenic cloned goats. Specifically, the SNRPN expression level of the abortion group was higher than that of the $\mathrm{N}$ group, but the level of the $\mathrm{D}$ group was markedly lower than the $\mathrm{N}$ group (Figure 5G, $\mathrm{P}<0.01$ ). Moreover, the XIST expression levels of the abortion and D groups were significantly lower than the $\mathrm{N}$ group (Figure $5 \mathrm{H}, \mathrm{P}<0.01$ ). No significant differences were detected between the normal goats and death transgenic cloned goats regarding the expression levels of the remaining imprinted genes (Figure 5B, C, and F; P > 0.05).
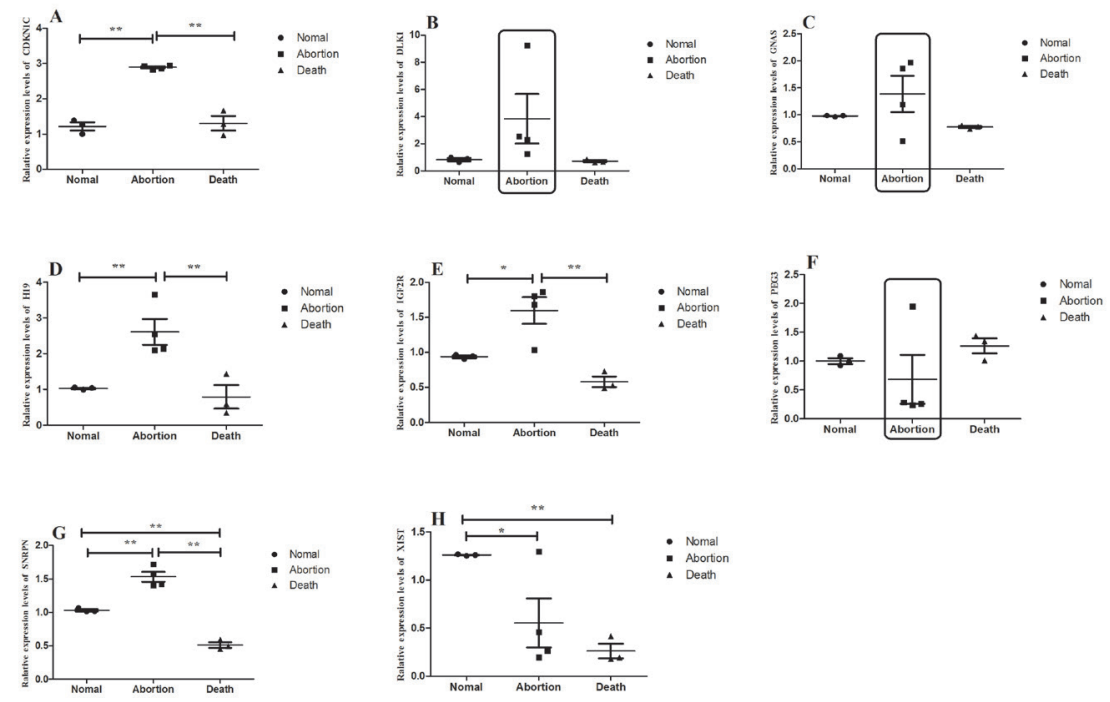

Figure 5. Relative expression levels of imprinted genes in heart tissues. A. B. C. D. E. F. G. H. Relative CDKN1C, DLK1, GNAS, H19, IGF2R, PEG3, SNRPN, and XIST expression levels in heart tissues of different groups, respectively. Normal $=$ control group of normal goats; Abortion = abortion group of transgenic cloned goats; Death = postnatal death group of transgenic cloned goats. Sections surrounded with the black pane represent significant individual differences in the expression of imprinted genes, but there were no significant differences between the normal and abortion groups. ${ }^{* *}$ Remarkably significant differences $(P<0.01)$. ${ }^{*}$ Significant differences $(P<0.05)$. 


\section{Relative expression levels of imprinted genes in the liver}

Compared to the normal group, the expression levels of CDKN1C and PEG3 were significantly higher in the abortion group (Figure $6 A$ and $F ; P<0.01$ and $P<0.01$, respectively), and the $\mathrm{D}$ group (Figure $6 \mathrm{~A}$ and $\mathrm{F} ; \mathrm{P}<0.05$ and $\mathrm{P}<0.01$, respectively). However, the GNAS expression levels were significantly lower in the abortion and $\mathrm{D}$ groups (Figure $6 \mathrm{C}$; $\mathrm{P}<0.05$ and $\mathrm{P}$ $<0.01$, respectively).

The $D L K 1$ expression levels of the abortion group were significantly lower than the $\mathrm{N}$ and $\mathrm{D}$ groups (Figure 6B, $\mathrm{P}<0.01$ ). Contrarily, the $H 19, I G F 2 R$, and $X I S T$ expression levels of the abortion group were significantly higher than those of the $\mathrm{N}$ group (Figure $6 \mathrm{D}$, $\mathrm{E}$, and $\mathrm{H} ; \mathrm{P}<0.05, \mathrm{P}$ $<0.05$, and $P<0.01$, respectively). No significant differences were detected between the SNRPN expression levels of normal and death transgenic cloned (Figure 6G, P > 0.05).
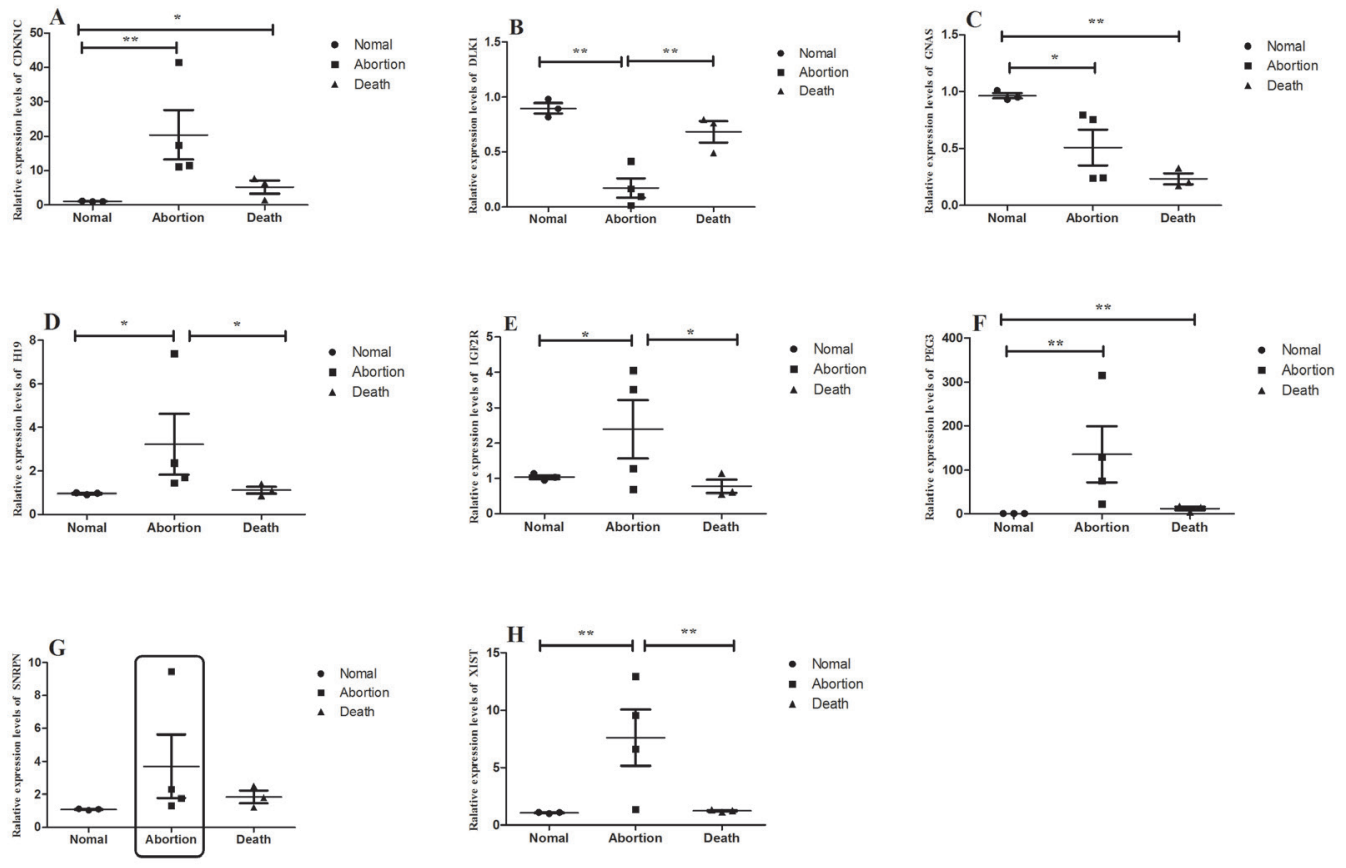

Figure 6. Relative expression levels of imprinted genes in liver tissues. A. B. C. D. E. F. G. H. Relative CDKN1C, DLK1, GNAS, H19, IGF2R, PEG3, SNRPN, and XIST expression levels in liver tissues of different groups; Normal = control group of normal goats; Abortion = abortion group of transgenic cloned goats; Death = postnatal death group of transgenic cloned goats. Sections surrounded with the black pane represent significant individual differences in the expression of imprinted genes, but there were no significant differences between the normal and abortion groups. ${ }^{* *}$ Remarkably significant differences $(P<0.01)$. * Significant differences $(P<0.05)$.

\section{Relative expression levels of imprinted genes in the spleen}

Compared to the normal group, the DLK1 expression level was significantly higher in the abortion and $\mathrm{D}$ groups (Figure $7 \mathrm{~B}, \mathrm{P}<0.01$ ), but GNAS expression was significantly lower in the abortion group (Figure 7C, $\mathrm{P}<0.01$ ). Furthermore, the H19, IGF2R, PEG3, SNRPN, and XIST 
expression levels were striking reduced in the abortion (Figure 7D-H; $\mathrm{P}<0.01, \mathrm{P}<0.05, \mathrm{P}<0.01$, $P<0.01$, and $P<0.01$, respectively) and $D$ groups (Figure 7D-H; $P<0.01, P<0.01, P<0.01, P$ $<0.05$, and $P<0.01$, respectively) as compared to the $N$ group. No significant differences were detected in CDKN1C expression levels (Figure 7A, $\mathrm{P}>0.05$ ).
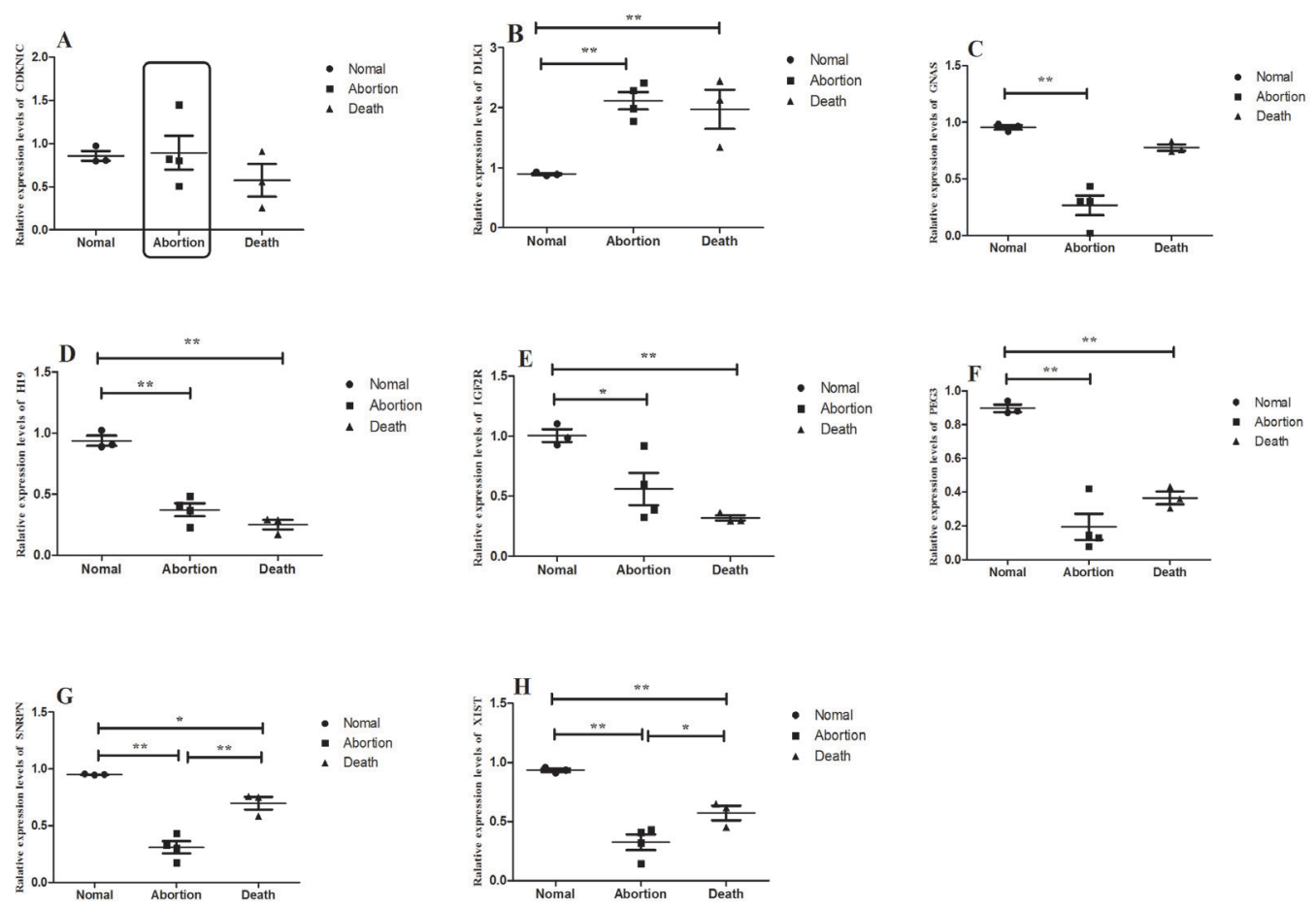

Figure 7. Relative expression levels of imprinted genes in spleen tissues. A. B. C. D. E. F. G. H. Relative CDKN1C, DLK1, GNAS, H19, IGF2R, PEG3, SNRPN, and XIST expression levels in the spleen tissues of different groups; Normal = control group of normal goats; Abortion = abortion group of transgenic cloned goats; Death = postnatal death group of transgenic cloned goats. Sections surrounded with the black pane represent significant individual differences in the expression of imprinted genes, but there were no significant differences between the normal and abortion groups. ${ }^{* *}$ Represents remarkably significant differences $(P<0.01)$. ${ }^{*}$ Represents significant differences $(P<0.05)$.

\section{Relative expression levels of imprinted genes in the kidney}

In the abortion group, the CDKN1C, DLK1, GNAS, H19, IGF2R, and PEG3 expression levels were visibly increased (Figure 8A-F; $\mathrm{P}<0.01, \mathrm{P}<0.01, \mathrm{P}<0.01, \mathrm{P}<0.01, \mathrm{P}<0.05$, and $P<0.05$, respectively), whereas the $X I S T$ expression level was significantly reduced (Figure $8 \mathrm{H}$, $\mathrm{P}<0.01$ ) as compared to the $\mathrm{N}$ group. Moreover, $P E G 3$ expression levels in the abortion group were discernibly lower than those of the $\mathrm{N}$ group (Figure $8 \mathrm{~F}, \mathrm{P}<0.05$ ). There were no significant differences in SNRPN expression (Figure 8G, $\mathrm{P}>0.05$ ). 

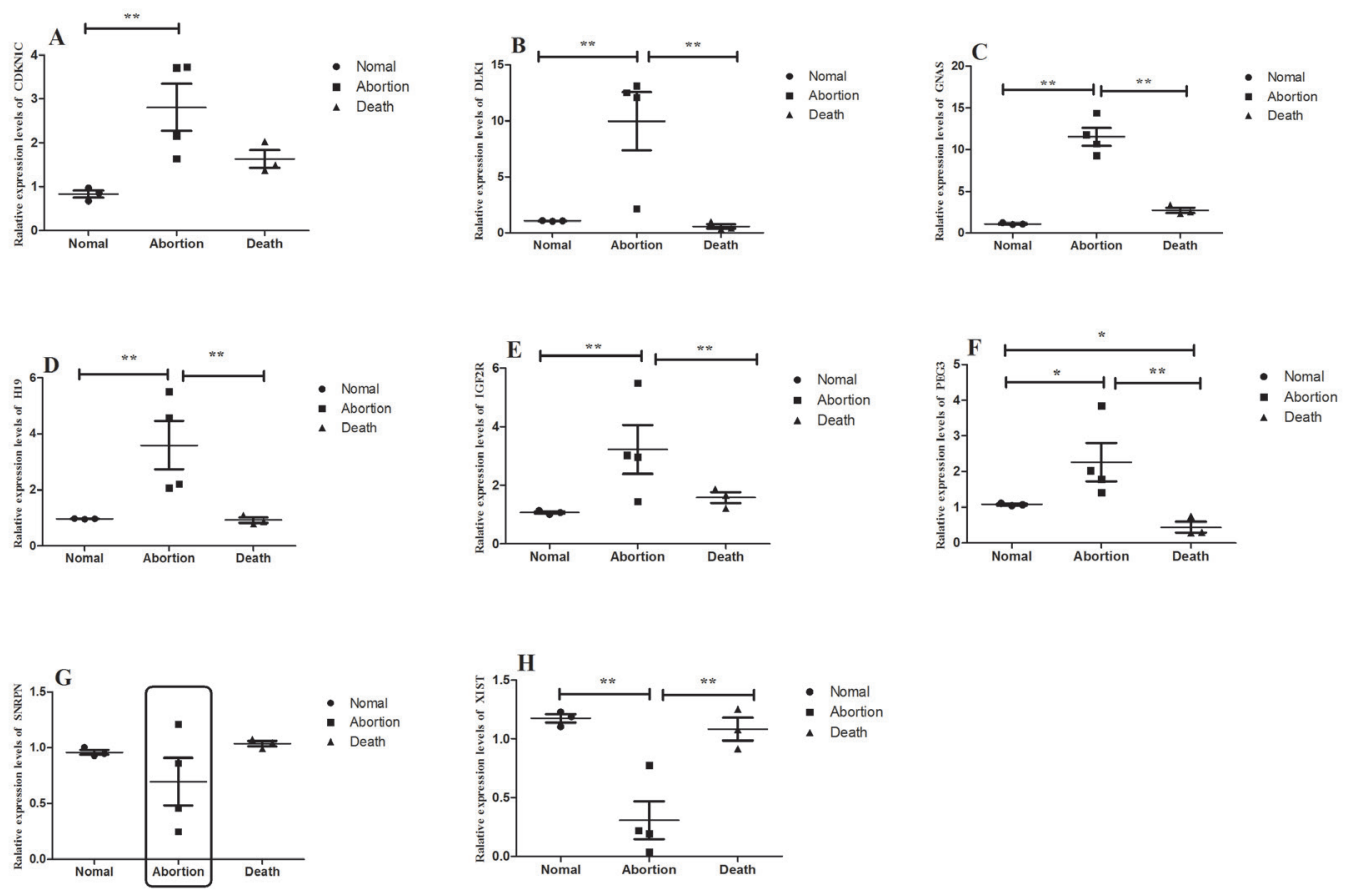

Figure 8. Relative expression levels of imprinted genes in kidney tissues. A. B. C. D. E. F. G. H. Represent the relative CDKN1C, DLK1, GNAS, H19, IGF2R, PEG3, SNRPN, and XIST expression levels in the kidney tissues of different groups; Normal = control group of normal goats; Abortion = abortion group of transgenic cloned goats; Death $=$ postnatal death group of transgenic cloned goats. Sections surrounded with the black pane represent significant individual differences in the expression of imprinted genes, but there were no significant differences between the normal and abortion groups. ${ }^{* *}$ Remarkably significant differences $(P<0.01) .{ }^{*}$ Significant differences $(P<0.05)$.

\section{DISCUSSION}

The possible negative long-term effects of cloning, as well as the high incidence of spontaneous abortion and abnormal birth observed in cloned animals, are causes for concern regarding attempts to clone animals for reproductive purposes. This study was performed to better understand why SCNT often results in a wide range of severe malformations such as neonatal edema, LOS, and immune system deficiencies. The examination of epigenetic information associated with imprinted genes during clonal development offers one method of addressing these questions.

Clear decreases of CDKN1C expression were observed in many types of malignancy, including hepatocarcinoma, esophageal cancer, and stomach carcinoma (Kavanagh and Joseph, 2011). Furthermore, abnormal expression of GNAS was associated with glucose-lipid metabolism disorder, and GNAS expression increased significantly in the livers of mice with hypercholesterolemia (Chen et al., 2005). Overexpression of GNAS promoted and aggravated hepatocarcinogenesis (Lambert et al., 2015). It was also demonstrated that high PEG3 expression levels were closely associated with primary liver cancer and renal developmental defects (Ludgate et al., 2013; Shibata and Aburatani, 2014). In the present study, CDKN1C expression decreased, while GNAS 
and PEG3 increased significantly in the livers of the abortion and D groups. In addition, GNAS and $P E G 3$ expression increased significantly in the kidneys of the abortion group. The H\&E staining results from the abortion group indicated that inflammatory cell infiltration and glomerular nephritis characteristics were observed in the liver and kidney tissues, respectively, and inflammation cells were also present in the livers of the $D$ group. This result indicated that aberrant expression of these genes might contribute to organic developmental defects, which might lead to the abortion and death of transgenic cloned goats.

This study also found that some imprinted genes showed significant expression variation among different tissues within the same group. For instance, in the abortion group, CDKN1C exhibited higher expression in heart and kidney tissues but lower expression in liver tissues. Moreover, DLK1 was more highly expressed in spleen and kidney tissues but lower expression in liver tissues. The expression of GNAS, H19, IGF2R, PEG3, SNRPN, and XIST also had similar situations. Similarly, in the death group, higher expression of $P E G 3$ was observed in the liver, but expression was lower in spleen and kidney tissues. These results were consistent with reports of gene expression in cloned piglets (Jiang et al., 2007). Lack of expression found in mouse research indicated that $C D K N 1 C$ resulted in the excessive growth of the placenta and fetus, but its overexpression also induced fetal growth retardation and even death (Andrews et al., 2007; Tunster et al., 2011). The DLK1 higher expression levels were proportional to the deterioration of hepatocarcinogenesis (Huang et al., 2007; Jin et al., 2008). DLK1 knockout studies in mice also found evidence of growth retardation, skeletal deformities, and obesity (Lin et al., 2007). Higher PEG3 expression could affect liver and kidney development in humans, and the homozygous deletion of PEG3 in mice caused growth retardation and metabolic abnormalities (Li, 1999; Curley et al., 2005; Swaney et al., 2007; Champagne et al., 2009). These results indicated that aberrant expression (overexpression or low expression) of imprinted genes might cause abnormal growth and development of relevant organs. However, further research should be performed to examine the functional mechanisms of imprinted genes.

Furthermore, we found that expression disorders of imprinted genes were more severe in the abortion group than the born death group, and details are shown in Table 2. In the abortion group, five imprinting genes exhibited inordinate expression in the heart, and seven imprinting genes were abnormally expressed in the liver, spleen, and kidney. In the born dead group, there were two, three, six and one imprinted gene abnormally expressing in heart, liver, spleen and kidney tissues, respectively. These results indicated that there were relatively more developmental defects in the abortion transgenic cloned goats. Studies have shown that analysis of the RNA expression levels of imprinted genes is an important way to measure the degree of reprogramming in transgenic cloned embryos (Gong et al., 2012). Thus, significant aberrant expression of imprinted gene in the abortion group might reflect much lower reprogramming efficiency of transgenic cloned embryos. Aberrant expression of $H 19, I G F 2 R$, and XIST was detected in heart, liver, spleen, and kidney tissues of the abortion group. $\mathrm{H} 19$ is a sensitive imprinted gene, which contains a regulatory domain that is vulnerable to manipulation in vitro (Fauque et al., 2007). Moreover, H19 controls the gene expression of the imprinted gene network by recruiting MBD1, which is involved in individual growth and development (Monnier et al., 2013). The results of previous studies showed that a CpG-island in intron 2 of IGF2R carries a maternal-specific methylation imprint that could act as an imprinting signal to maintain the expression of the maternal allele. Consistent with this result, genomic DNA methylation is necessary for IGF2R expression from the maternal allele (Wutz et al., 2001). Furthermore, XIST expression regulates DNA methylation of the 5 ' region of the CpG 
island, which plays a key role in X chromosome inactivation (Zhao et al., 2011). These data indicate that DNA methylation acts as a key mechanism that regulates genomic imprinting. Consequently, imprinted gene expression disorders could reflect abnormal DNA methylation associated with the growth and development of transgenic cloned goats.

Table 2. List of significant differences in abortion and born death groups as compared to the normal group.

\begin{tabular}{|c|c|c|c|}
\hline \multirow{2}{*}{ Tissues } & \multirow{2}{*}{ Gene name } & Significant difference & Significant difference \\
\hline & & A vs $\mathrm{N}$ & $\mathrm{D} v s \mathrm{~N}$ \\
\hline \multirow{8}{*}{ Heart } & CDKN1C & $* * \uparrow$ & No \\
\hline & $D L K 1$ & No & No \\
\hline & GNAS & No & No \\
\hline & H19 & $* * \uparrow$ & No \\
\hline & IGF2R & ${ }^{* \uparrow}$ & No \\
\hline & PEG3 & No & No \\
\hline & SNRPN & $* * \uparrow$ & $* \star \downarrow$ \\
\hline & $X I S T$ & $* \downarrow$ & $* \star \downarrow$ \\
\hline \multirow{8}{*}{ Liver } & $C D K N 1 C$ & $* * \uparrow$ & $* \uparrow$ \\
\hline & $D L K 1$ & $* \star \downarrow$ & No \\
\hline & GNAS & $* \downarrow$ & $* \star \downarrow$ \\
\hline & $\mathrm{H} 19$ & $* \uparrow$ & No \\
\hline & IGF2R & $* \uparrow$ & No \\
\hline & PEG3 & $* * \uparrow$ & $* * \uparrow$ \\
\hline & SNRPN & No & No \\
\hline & $X I S T$ & ${ }^{*} \downarrow$ & No \\
\hline \multirow{8}{*}{ Spleen } & $C D K N 1 C$ & No & No \\
\hline & $D L K 1$ & $* * \uparrow$ & $* * \uparrow$ \\
\hline & GNAS & $* \star \downarrow$ & No \\
\hline & $\mathrm{H} 19$ & $* * \downarrow$ & $* * \downarrow$ \\
\hline & IGF2R & $* \downarrow$ & $* * \downarrow$ \\
\hline & PEG3 & $* \star \downarrow$ & $* \star \downarrow$ \\
\hline & SNRPN & $* \star \downarrow$ & $\star \downarrow$ \\
\hline & $X I S T$ & $* * \downarrow$ & $* \star \downarrow$ \\
\hline \multirow{8}{*}{ Kidney } & CDKN1C & $\star \star \uparrow \uparrow$ & No \\
\hline & $D L K 1$ & $* * \uparrow$ & No \\
\hline & GNAS & $* * \uparrow$ & No \\
\hline & $\mathrm{H} 19$ & $* * \uparrow$ & No \\
\hline & IGF2R & $* * \uparrow$ & No \\
\hline & PEG3 & $* \uparrow$ & $\star \downarrow$ \\
\hline & SNRPN & No & No \\
\hline & $X I S T$ & $* \star \downarrow$ & No \\
\hline
\end{tabular}

$A=$ abortion group; $D=$ born death group; $N=$ normal group; **Remarkably significant difference $(P<0.01)$; ${ }^{*}$ Significant difference $(P<0.05)$; up-arrow $=$ increase; down-arrow = reduction.

In this study, all transgenic cloned goats were obtained using SCNT technology. Recent studies have suggested a link between the use of assisted reproductive techniques and an increase in normally rare imprinting disorders (Swales and Spears, 2005). In addition, the transfection, selection, and characterization procedures were requirements for the preparation of $h L F$ transgenic donor cells. And these procedures might alter the gene expression profile of donor cells, which might influence reprogramming efficiency of donor cells (Zhao et al., 2009). Therefore, abnormal imprinting gene expression in the heart, liver, spleen, and kidney tissues of transgenic cloned goats might originate from the incomplete reprogramming of donor somatic cells, which might be associated with transgenic cloning technology. However, further studies on these effects are required.

In summary, our study showed alterations of imprinting gene expression in both the abortion and born death groups, and greater expression irregularities were detected in the abortion 
group. Moreover, imprinting disorders in dead transgenic cloned goats may be due to the abnormal epigenetic modifications of donor cells during the reprogramming process. Increased knowledge of imprinted gene expression could provide clues to aid in our understanding of the molecular mechanisms associated with developmental defects in transgenic cloned goats, and it could also improve the low efficiency of transgenic technology in the future.

\section{Conflicts of interest}

The authors declare no conflict of interest.

\section{ACKNOWLEDGMENTS}

Research supported by the National Nature Science Foundation of China (\#31272443) and the National Major Special Projects on New Cultivation for Transgenic Organisms (\#2014ZX08008003 and \#2014ZX08008-004).

\section{REFERENCES}

Andrews SC, Wood MD, Tunster SJ, Barton SC, et al. (2007). Cdkn1c (p57Kip2) is the major regulator of embryonic growth within its imprinted domain on mouse distal chromosome 7. BMC Dev. Biol. 7: 53.http://dx.doi.org/10.1186/1471$\underline{213 X-7-53}$

Bischoff SR, Tsai S, Hardison N, Motsinger-Reif AA, et al. (2009). Characterization of conserved and nonconserved imprinted genes in swine. Biol. Reprod. 81: 906-920.http://dx.doi.org/10.1095/biolreprod.109.078139

Champagne FA, Curley JP, Swaney WT, Hasen NS, et al. (2009). Paternal influence on female behavior: the role of Peg3 in exploration, olfaction, and neuroendocrine regulation of maternal behavior of female mice. Behav. Neurosci. 123: 469480.http://dx.doi.org/10.1037/a0015060

Chen M, Gavrilova O, Zhao W-Q, Nguyen A, et al. (2005). Increased glucose tolerance and reduced adiposity in the absence of fasting hypoglycemia in mice with liver-specific Gs a deficiency. J. Clin. Invest. 115: 3217-3227.http://dx.doi.org/10.1172/ $\mathrm{JCl} 24196$

Constant F, Guillomot M, Heyman Y, Vignon X, et al. (2006). Large offspring or large placenta syndrome? Morphometric analysis of late gestation bovine placentomes from somatic nuclear transfer pregnancies complicated by hydrallantois. Biol. Reprod. 75: 122-130.http://dx.doi.org/10.1095/biolreprod.106.051581

Couldrey C and Lee RS (2010). DNA methylation patterns in tissues from mid-gestation bovine foetuses produced by somatic cell nuclear transfer show subtle abnormalities in nuclear reprogramming. BMC Dev. Biol. 10: 27.http://dx.doi. org/10.1186/1471-213X-10-27

Curley JP, Pinnock SB, Dickson SL, Thresher R, et al. (2005). Increased body fat in mice with a targeted mutation of the paternally expressed imprinted gene Peg3. FASEB J. 19: 1302-1304.

Fauque P, Jouannet P, Lesaffre C, Ripoche MA, et al. (2007). Assisted Reproductive Technology affects developmental kinetics, H19 Imprinting Control Region methylation and H19 gene expression in individual mouse embryos. BMC Dev. Biol. 7: 116.http://dx.doi.org/10.1186/1471-213X-7-116

Gong Z-J, Zhou Y-Y, Xu M, Cai Q, et al. (2012). Aberrant expression of imprinted genes and their regulatory network in cloned cattle. Theriogenology 78: 858-866.http://dx.doi.org/10.1016/j.theriogenology.2012.03.037

Huang J, Zhang X, Zhang M, Zhu J-D, et al. (2007). Up-regulation of DLK1 as an imprinted gene could contribute to human hepatocellular carcinoma. Carcinogenesis 28: 1094-1103.http://dx.doi.org/10.1093/carcin/bgl215

Jiang L, Jobst P, Lai L, Samuel M, et al. (2007). Expression levels of growth-regulating imprinted genes in cloned piglets. Cloning Stem Cells 9: 97-106.http://dx.doi.org/10.1089/clo.2006.0041

Jiang X, Yu Y, Yang HW, Agar NY, et al. (2010). The imprinted gene PEG3 inhibits Wnt signaling and regulates glioma growth. J. Biol. Chem. 285: 8472-8480.http://dx.doi.org/10.1074/jbc.M109.069450

Jin Z-H, Yang R-J, Dong B and Xing B-C (2008). Progenitor gene DLK1 might be an independent prognostic factor of liver cancer. Expert Opin. Biol. Ther. 8: 371-377.http://dx.doi.org/10.1517/14712598.8.4.371

Kavanagh E and Joseph B (2011). The hallmarks of CDKN1C (p57, KIP2) in cancer. Biochim. Biophys. Acta 1816: 50-56. 
Lambert M-P, Ancey P-B, Esposti DD, Cros M-P, et al. (2015). Aberrant DNA methylation of imprinted loci in hepatocellular carcinoma and after in vitro exposure to common risk factors. Clin. Epigenetics 7: 15.http://dx.doi.org/10.1186/s13148$\underline{015-0053-9}$

Li L, Keverne EB, Aparicio SA, Ishino F, et al. (1999). Regulation of maternal behavior and offspring growth by paternally expressed Peg3. Science 284: 330-333.http://dx.doi.org/10.1126/science.284.5412.330

Lin S-P, Coan P, da Rocha ST, Seitz H, et al. (2007). Differential regulation of imprinting in the murine embryo and placenta by the Dlk1-Dio3 imprinting control region. Development 134: 417-426.http://dx.doi.org/10.1242/dev.02726

Livak KJ and Schmittgen TD (2001). Analysis of relative gene expression data using real-time quantitative PCR and the 2($\Delta \Delta \mathrm{C}(\mathrm{T}))$ Method. Methods 25: 402-408.http://dx.doi.org/10.1006/meth.2001.1262

Ludgate JL, Le Mée G, Fukuzawa R, Rodger EJ, et al. (2013). Global demethylation in loss of imprinting subtype of Wilms tumor. Genes Chromosomes Cancer 52: 174-184.http://dx.doi.org/10.1002/gcc.22017

Madhavan J, Mallikarjuna K, Vikas K, George R, et al. (2010). CDKN1C (p57KIP2) mRNA expression in human retinoblastomas. Ophthalmic Genet. 31: 141-146.http://dx.doi.org/10.3109/13816810.2010.490544

Matoba S, Inoue K, Kohda T, Sugimoto M, et al. (2011). RNAi-mediated knockdown of Xist can rescue the impaired postimplantation development of cloned mouse embryos. Proc. Natl. Acad. Sci. USA 108: 20621-20626.http://dx.doi. org/10.1073/pnas.1112664108

Monnier P, Martinet C, Pontis J, Stancheva I, et al. (2013). H19 IncRNA controls gene expression of the Imprinted Gene Network by recruiting MBD1. Proc. Natl. Acad. Sci. USA 110: 20693-20698.http://dx.doi.org/10.1073/pnas.1310201110

Oczkowicz M, Piestrzyska-Kajtoch A, Piórkowska K, Rejduch B, et al. (2010). Expression of DLK1 and MEG3 genes in porcine tissues during postnatal development. Genet. Mol. Biol. 33: 790-794.http://dx.doi.org/10.1590/S1415$\underline{47572010000400030}$

Ogawa H, Ono Y, Shimozawa N, Sotomaru Y, et al. (2003). Disruption of imprinting in cloned mouse fetuses from embryonic stem cells. Reproduction 126: 549-557.http://dx.doi.org/10.1530/rep.0.1260549

Richard N, Molin A, Coudray N, Rault-Guillaume P, et al. (2013). Paternal GNAS mutations lead to severe intrauterine growth retardation (IUGR) and provide evidence for a role of XLas in fetal development. J. Clin. Endocrinol. Metab. 98: E1549-E1556.http://dx.doi.org/10.1210/jc.2013-1667

Shibata T and Aburatani H (2014). Exploration of liver cancer genomes. Nat. Rev. Gastroenterol. Hepatol. 11: 340-349.http:// dx.doi.org/10.1038/nrgastro.2014.6

Su JM, Yang B, Wang YS, Li YY, et al. (2011). Expression and methylation status of imprinted genes in placentas of deceased and live cloned transgenic calves. Theriogenology 75: 1346-1359.http://dx.doi.org/10.1016/j.theriogenology.2010.11.045

Suzuki J Jr, Therrien J, Filion F, Lefebvre R, et al. (2009). In vitro culture and somatic cell nuclear transfer affect imprinting of SNRPN gene in pre- and post-implantation stages of development in cattle. BMC Dev. Biol. 9: 9.http://dx.doi. org/10.1186/1471-213X-9-9

Swales AK and Spears N (2005). Genomic imprinting and reproduction. Reproduction 130: 389-399.http://dx.doi.org/10.1530/ rep.1.00395

Swaney WT, Curley JP, Champagne FA and Keverne EB (2007). Genomic imprinting mediates sexual experience-dependent olfactory learning in male mice. Proc. Natl. Acad. Sci. U. S. A. 104: 6084-6089.http://dx.doi.org/10.1073/pnas.0609471104

Tunster SJ, Van de Pette M and John RM (2011). Fetal overgrowth in the Cdkn1c mouse model of Beckwith-Wiedemann syndrome. Dis. Model. Mech. 4: 814-821.http://dx.doi.org/10.1242/dmm.007328

Wan Y-J, Zhang Y-L, Zhou Z-R, Jia R-X, et al. (2012). Efficiency of donor cell preparation and recipient oocyte source for production of transgenic cloned dairy goats harboring human lactoferrin. Theriogenology 78: 583-592.http://dx.doi. org/10.1016/j.theriogenology.2012.03.004

Wang M, Zhang X, Kang L, Jiang C, et al. (2012). Molecular characterization of porcine NECD, SNRPN and UBE3A genes and imprinting status in the skeletal muscle of neonate pigs. Mol. Biol. Rep. 39: 9415-9422.http://dx.doi.org/10.1007/ $\underline{\text { s11033-012-1806-6 }}$

Wrenzycki C, Herrmann D, Lucas-Hahn A, Korsawe K, et al. (2005). Messenger RNA expression patterns in bovine embryos derived from in vitro procedures and their implications for development. Reprod. Fertil. Dev. 17: 23-35.http://dx.doi. org/10.1071/RD04109

Wutz A, TheussI HC, Dausman J, Jaenisch R, et al. (2001). Non-imprinted Igf2r expression decreases growth and rescues the Tme mutation in mice. Development 128: 1881-1887.

Yang L, Chavatte-Palmer P, Kubota C, O'neill M, et al. (2005). Expression of imprinted genes is aberrant in deceased newborn cloned calves and relatively normal in surviving adult clones. Mol. Reprod. Dev. 71: 431-438.http://dx.doi.org/10.1002/ $\underline{\operatorname{mrd} .20311}$

Yang X, Smith SL, Tian XC, Lewin HA, et al. (2007). Nuclear reprogramming of cloned embryos and its implications for therapeutic cloning. Nat. Genet. 39: 295-302.http://dx.doi.org/10.1038/ng1973 
Zhao L, Zhao G, Xi H, Liu Y, et al. (2011). Molecular and DNA methylation analysis of Peg10 and Xist gene in sheep. Mol. Biol. Rep. 38: 3495-3504.http://dx.doi.org/10.1007/s11033-010-0460-0

Zhao MT, Lin H, Liu FJ, Quan FS, et al. (2009). Efficiency of human lactoferrin transgenic donor cell preparation for SCNT. Theriogenology 71: 376-384.http://dx.doi.org/10.1016/j.theriogenology.2008.08.004 